\title{
In vitro identification of a stem cell population from canine hair follicle bulge region
}

\author{
Raquel V.G. de Castro ${ }^{\mathrm{a}, *}$, Mariana R. Tavares ${ }^{\mathrm{a}}$, Fabiana F. Bressan ${ }^{\mathrm{b}, \mathrm{c}}$, Naira C.G. Pieri ${ }^{\mathrm{d}}$, \\ Amanda Baracho Trindade Hill ${ }^{\mathrm{a}}$, Aline F. Souza ${ }^{\mathrm{b}}$, Nathan da R.N. Cruz ${ }^{\mathrm{e}}$, Daniele S. Martins ${ }^{\mathrm{b}, \mathrm{c}}$, \\ Carlos E. Ambrósio ${ }^{\mathrm{b}}$, Flávio V. Meirelles ${ }^{\mathrm{b}}$, Joaquim M. Garcia ${ }^{\mathrm{a}}$ \\ ${ }^{a}$ Department of Preventive Veterinary Medicine and Animal Reproduction, Faculty of Agricultural and Veterinary Sciences, São Paulo State University, Jaboticabal/SP, \\ Brazil \\ ${ }^{\mathbf{b}}$ Department of Veterinary Medicine, Faculty of Animal Science and Food Engineering, University of São Paulo, Pirassununga/SP, Brazil \\ ${ }^{\mathrm{c}}$ Department of Surgery, Faculty of Veterinary Medicine and Animal Sciences, University of São Paulo, São Paulo/SP, Brazil \\ ${ }^{\mathrm{d}}$ Department of Animal Reproduction, Faculty of Veterinary Medicine and Animal Science, University of São Paulo, São Paulo/SP, Brazil \\ ${ }^{\mathrm{e}}$ Department of Veterinary Clinical and Surgery, Faculty of Agricultural and Veterinary Sciences, São Paulo State University, Jaboticabal/SP, Brazil
}

\section{A R T I C L E I N F O}

\section{Keywords:}

Skin

OCT4

CD200

CD34

Dog

\begin{abstract}
A B S T R A C T
Skin is an extensive and easily accessible organ possessing various cell types that are constantly renewed. Previous studies have suggested the presence of a stem cell niche at the bulge region of the hair follicle, which contains cells positive for CD200 and CD34. Thus, this study sought to identify these cell populations in canine skin cells using the following methods 1- collecting samples of adult and fetal skin and isolating and culturing these cells using a method of simple enzymatic digestion and 2- testing the cell cultures for CD200 and CD34 in vitro and comparing them with skin tissue samples (in situ). Immunofluorescence results were negative for both CD200 and CD34 in frozen and paraffin embedded tissue, whereas the analysis showed that cultured cells positive for CD34, CD200 and double positive cells could be visualized in different percentages. Additionally, the pluripotency marker OCT4 was positive in the isolated cells. Analysis of CD34, CD200 and OCT4 by RT-qPCR showed that there is expression in fetal and adult cells, although no difference was observed between groups. Our results suggest that bulge stem cells from both fetuses and adult dogs were reported with the use of CD34 and CD200 markers in this study, and further techniques for cell isolation and in vitro cultivation are needed in order to obtain enriched populations of skin stem cells in dogs.
\end{abstract}

\section{Introduction}

The skin is a complex and extensive organ comprising multiple organized cell arrangements derived from the embryonic layers. The skin's two primary layers are the epidermis, which originates from the ectodermal layer, and the dermis, which originates from the mesenchymal layer (Blanpain and Fuchs, 2006). Epidermis and its appendages contain specialized epithelial cells and keratinocytes, whereas the dermis mostly consists of mesenchymal cells (Lanza et al., 2012).

Skin lesions, such as extensive burns and large wounds, are common occurrences in routine veterinary practice. Thus, finding a graft that functions as a skin substitute in skin lesion cases is a subject of many studies. Green et al. described that once a considerable number of cells were available through laboratory cell culture, a patient's own keratinocyte mesh was employed successfully for the regeneration of human skin lesions (Green, 2008). However, according to Tan et al. (2014), a disadvantage of using the patient's own cells is the long period of time required before a significant sample of cells could be obtained for application (Tan et al., 2014). These authors, therefore, suggest the use of fetal skin cells as a possible substitute for autologous cells. Thus, the evaluation of cell cultures derived from fetuses and adults is important for the establishment of a more suitable skin substitute.

Previous studies have proven the existence of hair follicle bulge stem cell niches in mice, humans and dogs (Cotsarelis et al., 1990; Lyle et al., 1998; Pascucci et al., 2006). Analyzing mice follicle cells, Cotsarelis et al. (1990) identified a slow-cycling cell population capable of retaining a tritiated thymidine stain during its cell cycle at the outer root sheath of the hair. Later, Morris and Potten (1999) associated this population of cells with keratinocyte stem cells (Morris and Potten, 1999). These cells, which are self-renewable and responsible for

\footnotetext{
* Corresponding author at: Departamento de Medicina Veterinária Preventiva e Reprodução Animal - Faculdade de Ciências Agrárias e Veterinárias, Universidade Estadual Paulista, Via de Acesso Prof. Paulo Donato Castellane, s/n, 14884-900 - Jaboticabal, São Paulo, Brazil.

E-mail address: rvgcastro@hotmail.com (R.V.G. de Castro).
} 
maintaining the homeostasis of the tissue, are slow-cycling in vivo and can be activated whenever wounds emerge. Additionally, conditions provided by the cell culture medium in vitro indicate a high proliferative potential (Lavker and Sun, 2000). These cells are capable of generating epidermal cells and hair follicles, and therefore, this region is responsible for providing cells not just for the growth of new hair but also for the regeneration of the skin (Taylor et al., 2000).

CD200 has already been found in the hair follicle bulge of human skin (Inoue et al., 2009; Kloepper et al., 2008; Ohyama et al., 2006). In dogs, mRNA for K15, CD200 and follistatin in addition to sebaceous gland lineage markers were found in the bulge within reconstituted pilosebaceous structures, suggesting the canine bulge stem cells have contributed to the reorganization not just of hair follicles but also of sebaceous glands (Kobayashi et al., 2010). This makes the multipotency of cells evident in this region. Similarly, CD200 is a molecule associated with the diminishment of graft rejection and immune system regulation (Rosenblum et al., 2004; Yu et al., 2013).

CD34 is a well-known hematopoietic stem cell marker that has been found to be positive for cells at the follicular bulge region in mice and canines (Pascucci et al., 2006; Trempus et al., 2003), although interestingly, it is not found in the human bulge (Inoue et al., 2009; Poblet et al., 2006). Previous studies found that it is possible to isolate living cells from this region through the use of fluorescence-activated cell sorting (FACS) using a CD34 marker (Tumbar et al., 2004). Similarly, a positive CD34 population was obtained with magnetic separation, and these cells were differentiated into neural cells (Najafzadeh et al., 2015).

Some proteins are known for their presence in pluripotent cells. The OCT4 expression occurs in germinal lineages during the preimplantation of embryos and post-implantation epiblasts, making it ideal for the identification of pluripotent stem cells (Shi and Jin, 2010). For this reason, the presence of these stem cells was also monitored in our research.

Thus, the objective of this experiment was to prove the existence of cell populations of CD34 and CD200 within the hair follicle bulge, which could be obtained through simple enzymatic digestion methods. These cells, once identified, could be utilized in basic or applied research protocols, such as in regenerative medicine. Therefore, the isolation and in vitro culture of cells derived from fetal and adult canine skin, the labeling of membrane proteins and the quantification of transcripts known to be present in the stem cells of the hair follicle were conducted.

\section{Materials and methods}

\subsection{Sample collection}

The procedures from this work were approved by the ethical committee for the use of animals (CEUA) from the "Faculdade de Ciências Agrárias e Veterinárias/Faculdade de Ciências Agrárias e Veterinárias da UNESP - Jaboticabal - FCAV, UNESP" under protocol number 011904/14.

Fragments of skin from adult animals utilized in this study were collected from routine surgeries performed at the "Hospital Veterinário Governador Laudo Natel" at FCAV/UNESP with the consent of the animals' owners. For samples, a healthy skin fragment with a surface area of approximately $1 \mathrm{~cm}^{2}$ was obtained from each animal $(\mathrm{n}=3)$. Preference was given to extractions during orthopedic surgery, as incisions are generally made at skin regions rich in hair follicles, such as the limbs or the dorsum of an animal.

Fetal skin fragments were obtained from routine surgeries performed at the Obstetrics Department of the same institution. For fetal cell isolation, fragments from three fetuses from different females, aged between 40 and 45 days, were collected from the lateral thoracic region. Fetal age was determined by measuring the distance between the atlanto-occipital joint and the sacrum, as described earlier (Evans and
Sack, 1973; Pieri et al., 2015).

\subsection{Histological analysis: hematoxylin and eosin staining (HE)}

Skin samples collected from the adults and fetuses were frozen in Tissue-Tek O.C.T. Compound Medium (SAKURA N ${ }^{\circ}$ Cat. SAKU-4583) and stored in a freezer at $-80^{\circ} \mathrm{C}$. For sample analysis, frozen sections were infused in cold acetone and stored for $10 \mathrm{~min}$ at $-20^{\circ} \mathrm{C}$. They were then air dried and placed in $100 \%$ alcohol for five minutes, then $95 \%$ alcohol for $5 \mathrm{~min}, 70 \%$ alcohol for $5 \mathrm{~min}$, and then they were rinsed in running water for $5 \mathrm{~min}$. Samples were then placed briefly in hematoxylin and rinsed in running water. The slides were then briefly placed in eosin and rinsed in running water. Another alcohol passage at $70^{\circ}$ was performed, followed by another at $95^{\circ}$, two more at alcohol $100^{\circ}$, one using a mixture of alcohol and xylene (1:1), and then three passages using xylene only. A drop of Permount mounting medium (Fisher Scientific) was added to the section, and a cover slide was added. The analysis was performed using Olympus IX70 fluorescence microscopy.

\subsection{Immunofluorescence of frozen and paraffin embedded tissues}

Collected skin samples were frozen in Tissue-Tek O.C.T. Compound Medium (SAKURA $\mathrm{N}^{\circ}$ Cat. SAKU-4583) and stored in a freezer at $-80^{\circ} \mathrm{C}$. For analysis of the frozen tissue, $5 \mu \mathrm{m}$ histological sections were made in a cryostat (SLEE Mainz MEV) and placed on Star Frost ${ }^{\circ}$ slides, which were then air dried for $30 \mathrm{~min}$ and fixed in cold acetone for $10 \mathrm{~min}$ in a freezer. For analysis of paraffin embedded tissues, the samples were fixed for $24 \mathrm{~h}$ in $4 \%$ in PFA, dehydrated in ethanol, and embedded in paraffin. Next, $5 \mu \mathrm{m}$ thick sections were cut with a microtome.

For immunofluorescence staining, three 5-min rinses in tris-buffered saline (TBS) were performed, then the sample was blocked with $10 \%$ goat serum for one hour in a humidified chamber. After this period, the primary antibodies (Table 1) were added to the sections. For the control section, only TBS with $1 \%$ goat serum was added. The sections were maintained in a humidified chamber at $4{ }^{\circ} \mathrm{C}$ overnight. The following morning, another set of three 5 -min rinses with TBS with $1 \%$ goat serum was performed, and the secondary antibody was added at a 1:500 dilution rate for one hour. After rinsing, PROLONG ${ }^{\circ}$ (Gold Antifade Reagent with DAPI $-\mathrm{N}^{\circ}$ Cat. P36935 ThermoFisher Scientific) was used before slide covers were added. The analysis was performed using Olympus IX70 fluorescence microscopy.

\subsection{Cell isolation and in vitro culture}

For cell isolation, healthy skin fragments with a surface area of approximately $1 \mathrm{~cm}^{2}$ of both canine fetuses and adults were cleaned, and the subcutaneous tissue was removed. Then, the skin samples were submitted to the process of simple enzymatic digestion, which consists

Table 1

Antibodies used for dog skin stem cell characterization.

\begin{tabular}{|c|c|c|c|c|c|}
\hline Antibodies & Brand & $\begin{array}{l}\text { Catalog } \\
\text { number }\end{array}$ & Type & Species & Dilution \\
\hline CD34 & Santa Cruz & Sc7045 & Polyclonal & Goat & $1: 50$ \\
\hline CD200 & Santa Cruz & Sc323725 & Polyclonal & Goat & $1: 50$ \\
\hline OCT4 & Santa Cruz & Sc8629 & Monoclonal & Goat & $1: 100$ \\
\hline $\begin{array}{l}\text { Alexa Fluor } 488 \\
\text { Anti-goat } \\
\text { IgG }\end{array}$ & ThermoFisher & A11078 & Polyclonal & Rabbit & $1: 500$ \\
\hline $\begin{array}{l}\text { Alexa Fluor } 680 \\
\text { Anti-goat } \\
\text { IgG }\end{array}$ & ThermoFisher & A21084 & Polyclonal & Donkey & $1: 500$ \\
\hline
\end{tabular}

Antibodies used for immunofluorescence, immunocytochemistry and flow cytometry. 
Table 2

Sequences of the primers used for RT-qPCR.

\begin{tabular}{|c|c|c|c|}
\hline Genes & $5^{\prime}-3^{\prime}$ Forward primer & $5^{\prime}-3^{\prime}$ Reverse primer & Annealing $\left({ }^{\circ} \mathrm{C}\right)$ \\
\hline GADPH & CTTCACCACCATGGAGAAGC & CAGCTCAGGGATGACCTTGC & 60 \\
\hline $18 \mathrm{~S}$ & CCTGCGGCTTAATTTGACTC & CTGTCAATCCTGTCCGTGTC & 60 \\
\hline OCT4 & GGTGGAGGAAGCTGACAACA & GTTCGCTTTCTCTTTCGGGC & 60 \\
\hline CD34 & CCAAGTACCATCAAGGGAGA & GTCTTCTGGGTGGCAGTGAT & 59.60 \\
\hline CD200 & TGGGAAGATCTCGGGAACAG & TTCGAAGAAGTTGTAGTGAAGAAACAC & 57.50 \\
\hline
\end{tabular}

of slicing the skin in fragments with an approximate surface area of $0.1 \mathrm{~cm}^{2}$ and incubating it with collagenase I digestion $(150 \mathrm{U} / \mathrm{ml}$ ThermoFisher Scientific $\mathrm{N}^{\circ}$ Cat. 17100-017) for three hours at $38.5^{\circ} \mathrm{C}$. After this period, a culture medium, described below, was added for enzyme neutralization. The suspension was then centrifuged at $300 \mathrm{~g}$ for 7 min to obtain a cell pellet, which was then plated in cell culture flasks with a surface area of $25 \mathrm{~cm}^{2}$ (CORNING ${ }^{\circ}$ ). The culture medium used was high glucose DMEM (ThermoFisher Scientific, $\mathrm{N}^{\circ}$ Cat. 12100-046) containing $50 \%$ of F-12 Nutrient Mixture (Ham's, ThermoFisher Scientific, $\mathrm{N}^{\circ}$ Cat. 21700-075), 0.5\% amikacin, $1 \%$ non-essential amino acids and $10 \%$ fetal bovine serum.

The isolated cells were then maintained in a cell culture incubator at $38.5{ }^{\circ} \mathrm{C}$ with $5 \% \mathrm{CO}_{2}$ and saturated humidity. The cell lineages obtained were cryopreserved as soon as they reached $90 \%$ confluence at the culture flask. The freezing medium used was comprised of $45 \%$ culture cell media, 45\% fetal bovine serum and 10\% DMSO.

\subsection{Immunocytochemistry of cultured cells}

For the immunocytochemistry assay, the cells were cultured in four well plates $\left(\mathrm{NUNC}^{\circ}\right)$. Once confluence of approximately $90 \%$ was reached, the cells were fixed in paraformaldehyde $4 \%$ for $15 \mathrm{~min}$ and then maintained in PBS until analysis. The analyzed cultures were rinsed with PBS with $0.1 \%$ Tween 20 (Synth) and $0.1 \%$ bovine serum albumin (BSA) (Sigma-Aldrich). The cells were then maintained in PBS with $1 \%$ Triton X-100 (Synth) for 20 min before being rinsed. Finally, the samples were blocked with $1 \%$ BSA for one hour. Primary antibodies were added (Table 1) and left overnight at $4{ }^{\circ} \mathrm{C}$. As negative control, primary antibodies were omitted. For the second day of analysis, the secondary antibody (Table 1) was added after the rinses and cells were kept for two hours at room temperature protected from light. After rinsing, PROLONG ${ }^{\circ}$ (Gold Antifade Reagent with DAPI $-\mathrm{N}^{\circ}$ Cat. P36935 Thermo Fisher Scientific) was added to PBS in the wells, and the cultures were visualized using fluorescence microscopy.

\subsection{Flow cytometry analysis of cultured cells}

Analyses of fetal and adult cell cultures were performed with a BD FACS cytometry, and the results were obtained using BD FACS Diva Version 6.1.3 (BD Biosciences) software. Briefly, cells were thawed and cultured until they reached approximately $90 \%$ confluence. Then, they were removed from the plates by adding $0.2 \%$ EDTA in PBS free from calcium and magnesium (DPBS), suspended in a $0.1 \%$ Tween 20 in DPBS solution and centrifuged at $300 \mathrm{~g}$ for $7 \mathrm{~min}$. Next, the supernatant was discharged and $500 \mu \mathrm{L}$ of blockage solution was added (1\% BSA in DPBS) for one hour. After centrifugation, the supernatant was removed, and the cells were incubated with $50 \mu \mathrm{L}$ of primary antibody (Table 1 ) for one hour at room temperature. Next, the sample was centrifuged with a DPBS of $0.1 \%$ Tween 20 and $0.1 \%$ BSA, and the samples were protected from light and incubated with $50 \mu \mathrm{L}$ of the secondary antibody (Table 1 ) for one hour. Then, a centrifugation with $0.1 \%$ BSA and $0.1 \%$ Tween 20 in DPBS was performed. The samples were then incubated with the second primary antibody for one hour, using the same methods as the first incubation. After this centrifugation, the samples were incubated with the second secondary antibody. Finally, samples were fixed with $200 \mu \mathrm{L}$ paraformaldehyde $4 \%$ in DPBS and kept in DPBS protected from light until analysis.

For each animal, two tubes were prepared: one CD200 and CD34 double labeled tube and one unlabeled tube. For CD200, the secondary antibody employed was Alexa Fluor 680, which was read by the red laser 680 filter of the APC channel. For CD34, an Alexa Fluor 488 secondary antibody was employed and was read by the blue laser 488 filter of the FITC channel.

\subsection{Quantitative reverse transcription polymerase chain reaction (RT-} $q P C R)$

Total RNA was isolated using RNeasy Micro Kit (\#74004 Qiagen) according to the manufacturer's protocol. RNA quantification was determined by the $260 / 280$ ratio using a spectrophotometer (DS-11-B, DeNovix), and cDNA synthesis was performed with a total of $100 \mathrm{ng} / \mu \mathrm{l}$ per sample using a High-Capacity Reverse Transcription kit (Applied Biosystems, CA, USA) following the manufacturer's protocol. PCR amplification of the gene transcripts (Table 2) was performed using a StepOne instrument with Power SYBR Green Master Mix (Applied Biosystems).

The PCR reactions were performed as follows: $95^{\circ} \mathrm{C}$ for $15 \mathrm{~min}, 45$ cycles of $95^{\circ} \mathrm{C}$ for $15 \mathrm{~s}, 60^{\circ} \mathrm{C}$ for $5 \mathrm{~s}, 72^{\circ} \mathrm{C}$ for $30 \mathrm{~s}$ and $72{ }^{\circ} \mathrm{C}$ for $2 \mathrm{~min}$. Melting curve analysis was performed to verify amplification of the specific products, and all reactions were performed in triplicate. Transcripts levels were determined by RT-qPCR and analyzed with LinReg PCR software (Version 2015.0). The cycle threshold (Ct) values of the target genes were normalized to geometric media GAPDH and $18 \mathrm{~S}$, and fold change was then calculated by the Pfaffl equation (Pfaffl, 2001). Statistical analyses consisted of analysis of variance (ANOVA, $\mathrm{p}<0.05$ ) followed by Tukey's test to determine the differences between gene expression and the group means $(\mathrm{p}<0.5)$ using $\mathrm{R}$ software (R Core Team, 2013).

\section{Results}

3.1. In situ analysis: histological and immunofluorescence analysis in skin tissues

Histological analysis was performed for visualization of the skin structures and for locating the bulge region. In adult sections, it was possible to recognize sebaceous glands and hair follicles, which were found mostly in transverse sections (Fig. 1a) and in some oblique sections (Fig. 1b); longitudinal sections, however, were not identified. Histological analysis of the assembled hair structures of the fetal tissues was performed (Fig. 1c), although the bulge region was not clearly observed in either the adult or fetal samples.

The immunofluorescence analysis for CD200 and CD34 membrane proteins was negative in the skin tissue (Fig. 2).

\subsection{Isolation and in vitro cell culture}

After the isolation and culture of the skin cells, they were initially observed for confluence and then frozen at first passage (P0). From the initial quantity of approximately $1 \mathrm{~cm}^{2}$ of collected skin, the visual 


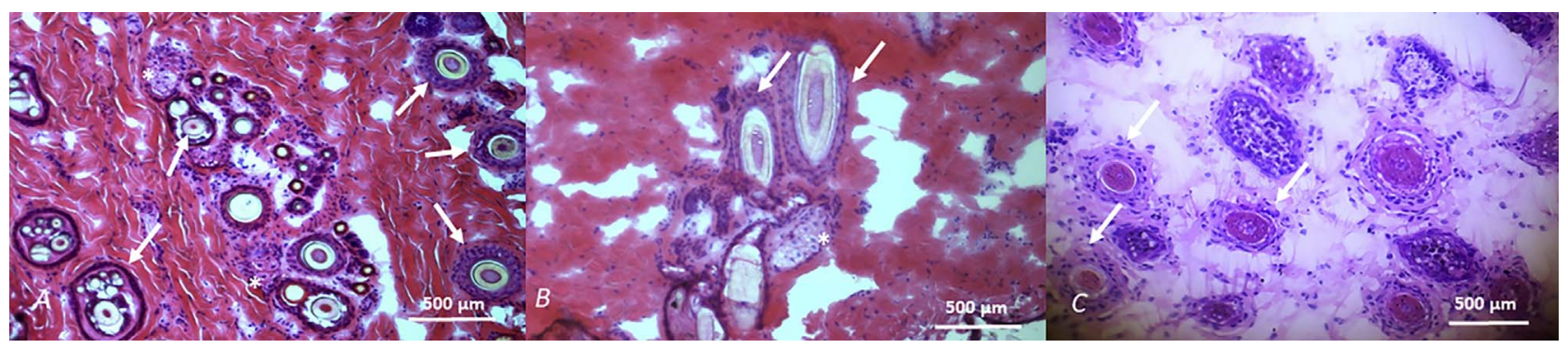

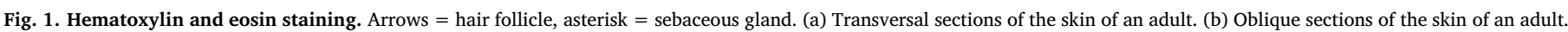
(c) Sections of the skin of a fetus of approximately 45 days of age.

analysis of the cell culture one day after isolation revealed a higher concentration of cells attached to the culture flask in the fetal cell culture than in the adult culture (Fig. $3 \mathrm{c}$ and a). Thus, the fetal cell cultures could be cryopreserved the day after isolation, whereas adult cells were cryopreserved only after approximately 10 days in culture.

Both the fetal and adult cell cultures clearly showed colonies of cells from distinct morphologies: fusiform and round. Hence, a mixed population of cells is expected in early cultures, since stem cells from the bulge region were probably isolated from explants together with fibroblasts, keratinocytes and others types of cells. Even though there is more than one population of cells, our bulge stem cell population is probably present in our culture, since we could identify double labeling for CD200 and CD34, markers found together specifically in bulge cells. It is important to mention that fetal cells used for the immunocytochemistry and flow cytometry experiments were taken from fetuses that were 45 days old. Because these samples were frozen on the next day of isolation, the formation of colonies with distinct morphologies could not occur. Thus, cell material from a fourth fetus with an approximate age of 58 days was cultured and frozen 15 days after its isolation. In this culture, it was possible to visualize colonies from the two morphologies identified (Fig. 3d). The round cells were generally located close to the hair when present at the plate (Fig. 3b), and they were tightly packed and contained a high nucleus to cytoplasmic ratio. In contrast, fusiform cells were elongated and had a smaller nucleus compared to the size of the cell.

\subsection{Immunocytochemistry for fetal and adult derived cell cultures}

The presence of the CD200, CD34 and OCT4 staining was investigated. OCT4 was only detected in fetal cells, whereas CD34 and CD200 were positive in both adult and fetal cell cultures (Fig. 4). For each marker, a control was conducted in which the primary antibody was omitted.

\subsection{Flow cytometry analysis}

For each of the samples, a total of 10,000 acquisitions were analyzed through flow cytometry. The mean percentages of positive cells are presented in Table 3 and Fig. 5. The percentage of cells positive for CD34 and CD200 was low in both the fetal and adult cells (ranging between 0.1 and $0.5 \%$ ). Cells positive for CD200 only were low in the adult cells (ranging between 0 and 0,4\%, Fig. 5) and negative in the fetal cells. CD34 was detected in both cell types $(12.7 \%$ and $29.0 \%$ on average for adult and fetal cells, respectively), with a slightly higher percentage found in fetal cells.

\subsection{Quantitative reverse transcription polymerase chain reaction (RT- qPCR)}

Transcripts for OCT4, CD34 and CD200 were detected in both fetal and adult cultured cells. Even if fetal cells seemed to express higher levels of OCT4 and CD34, no statistically significant differences were present. Analysis of the CD200 expression showed that, at the level of the transcripts, the fetal and adult cells were very similar (Fig. 6).

\section{Discussion}

The observed differences between the speed of growth for fetal cell cultures and adult cell cultures are in accordance with previous data (Tan et al., 2014), which reported that keratinocyte proliferation is faster in fetal cells than it is in adult cells. In our experiment, the fetal culture reached subconfluency in approximately one day, whereas adult cultures needed approximately 10 days to reach subconfluency. Although this first observation is interesting and consistent with previous findings, a doubling of the time for the analysis for each lineage was not possible to be performed once the cells presented senescence signs early in the third passage (data not shown).

The bulge region is located between the opening of the sebaceous

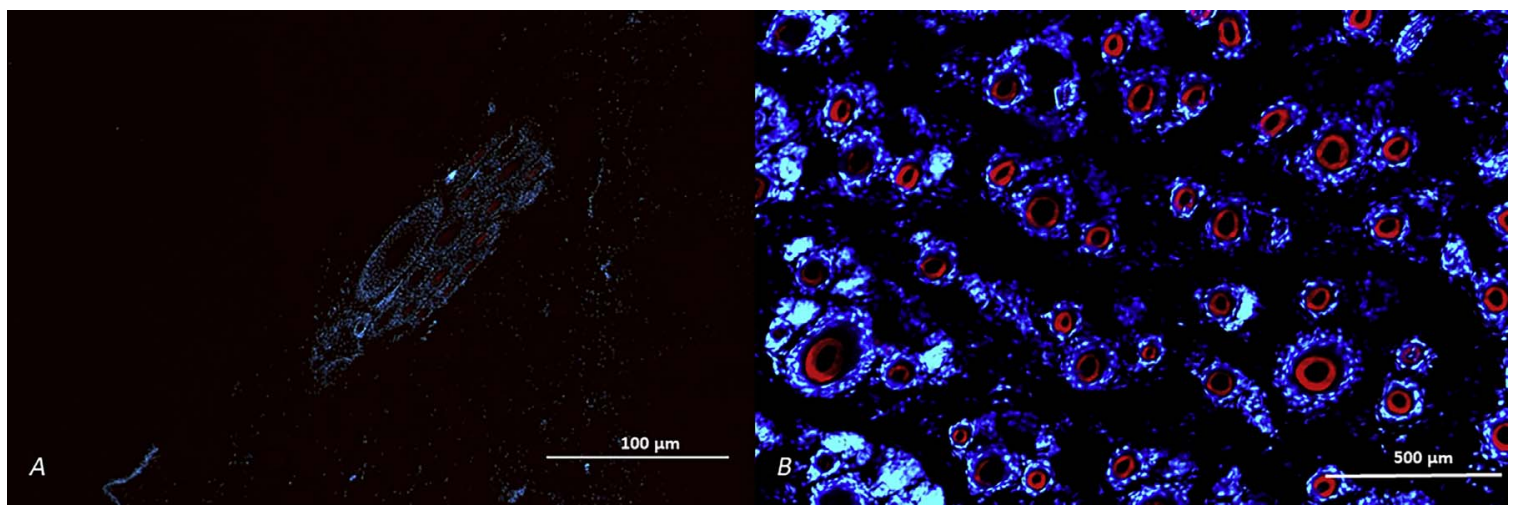

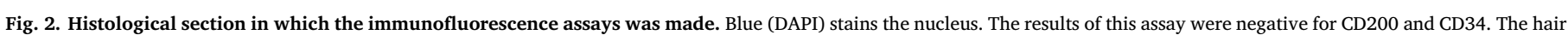

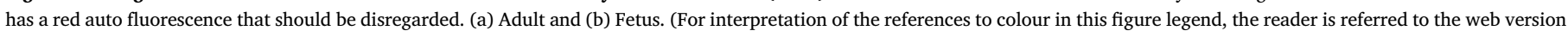
of this article.) 


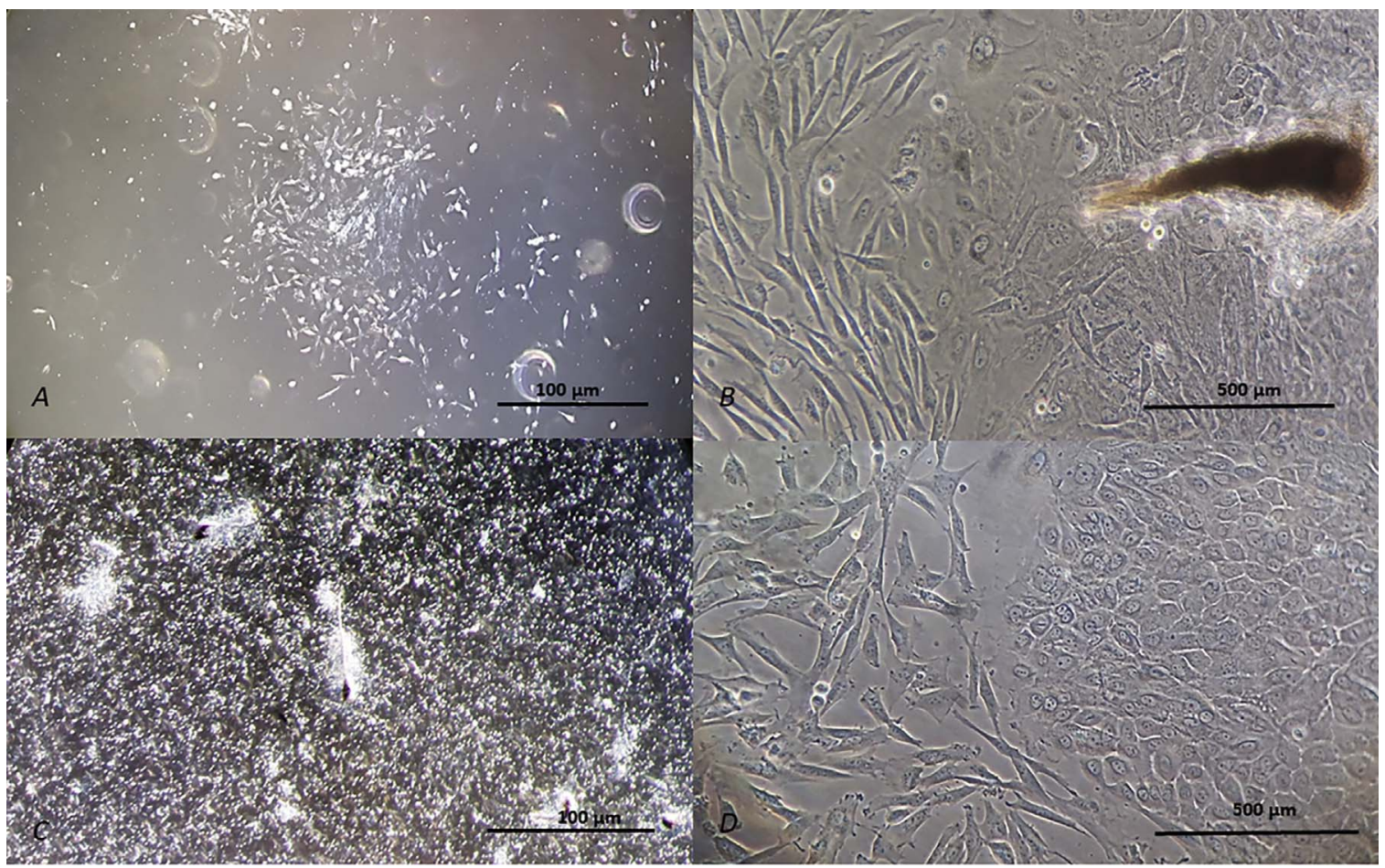

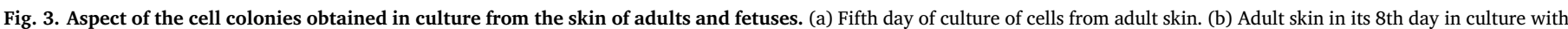

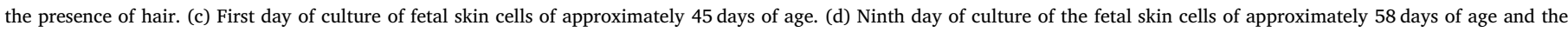
presence of colonies with two distinct morphologies.

gland duct and the insertion point of the arrector pili muscle at the outer root sheath (Kobayashi et al., 2010; Ohyama et al., 2006; Pascucci et al., 2006). Our results for HE staining of the skin samples demonstrated that the sections were transverse or oblique, and the bulge region was not necessarily present in all cases. According to Pascucci et al. (2006), CD34 staining was found in the canine follicular isthmic region, at the basal layer of the outer root sheath, and it was generally not found in the suprabulbar region. Occasionally, however, the layer immediately above the basal cells was reactive with CD34. On the other hand, Gerhards et al. (2016) reported that both the lower isthmic region and the upper suprabulbar region of the canine anagen hair follicle stained positively for CD34 (Gerhards et al., 2016).

Previous research has proven the presence of CD200 protein in human skin cells and mice skin cells (Inoue et al., 2009; Ohyama et al., 2006; Rosenblum et al., 2004). In humans, CD200 staining was found by Ohyama et al. (2006) to be restricted to the outermost layer of the outer root sheath in the region defined as the bulge region, i.e., the region between the arrector pili muscle insertion and the opening of the

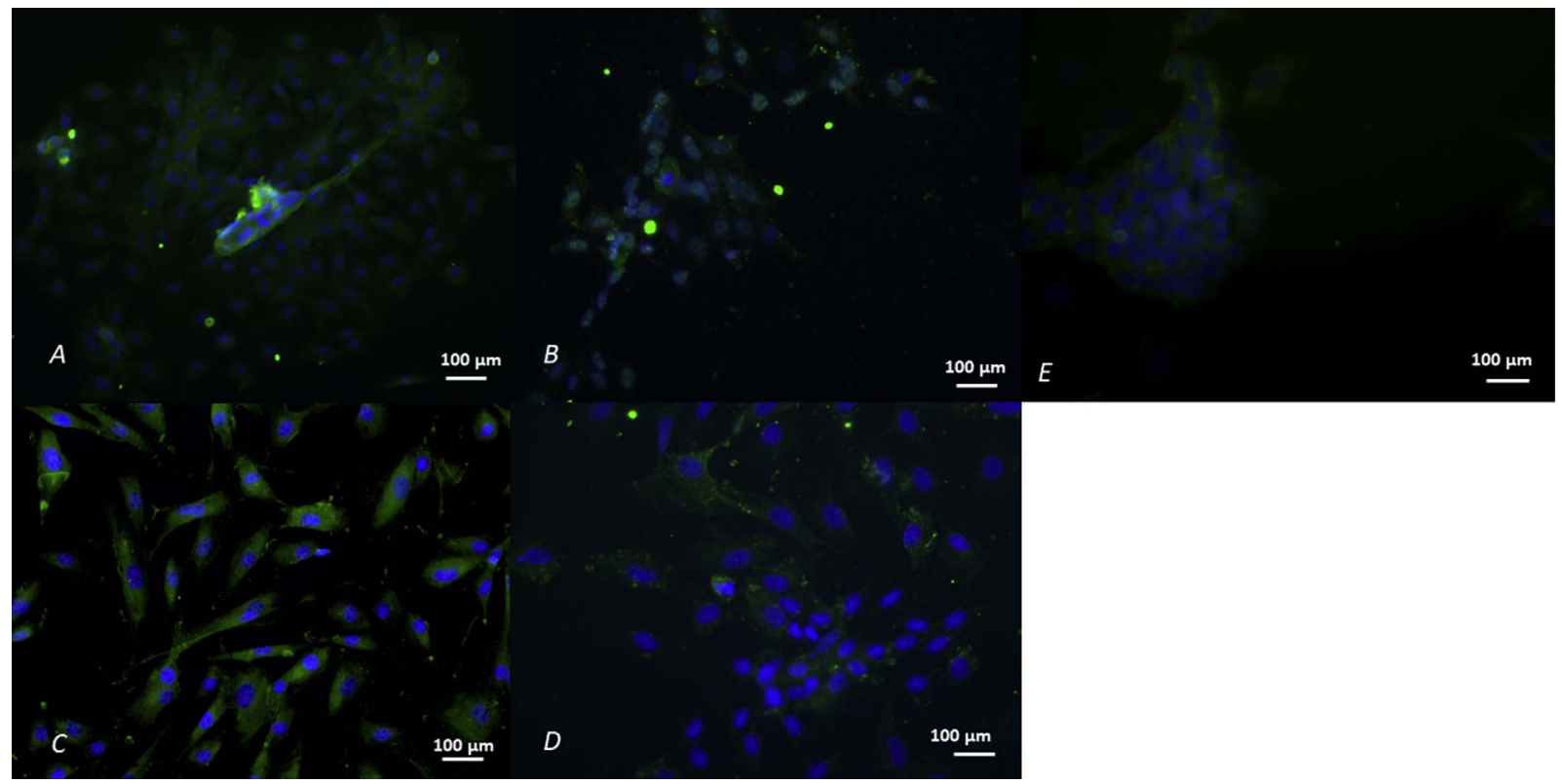

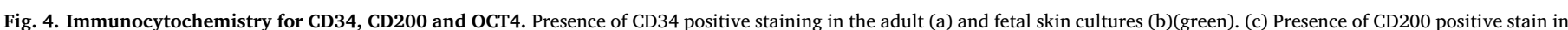

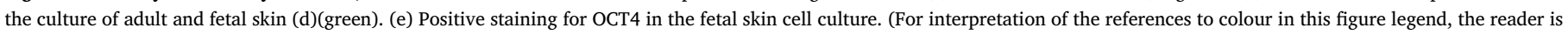
referred to the web version of this article.) 
Table 3

Detection of CD200 and CD34 through flow cytometry.

\begin{tabular}{lllllllll}
\hline \multicolumn{1}{l}{ Positive cells (\%) } & 110 & & & \\
\hline Label & $1 \mathrm{~A}$ & $2 \mathrm{~A}$ & $3 \mathrm{~A}$ & $1 \mathrm{~F}$ & $2 \mathrm{~F}$ & $3 \mathrm{~F}$ & $\begin{array}{l}\text { Adult } \\
\text { average }\end{array}$ & $\begin{array}{l}\text { Fetal } \\
\text { average }\end{array}$ \\
\hline CD200 & 0.4 & 0.1 & 0.0 & 0.0 & 0.0 & 0.0 & 0.17 & 0.0 \\
CD34 & 2.7 & 8.3 & 27.2 & 36.5 & 14.3 & 36.3 & 12.7 & 29.0 \\
CD200/ & 0.4 & 0.3 & 0.3 & 0.1 & 0.1 & 0.5 & 0.3 & 0.2 \\
CD34 & & & & & & & & \\
\hline
\end{tabular}

Percentage of cells positive for CD200 + CD34, CD200 + and CD34 +.

sebaceous gland (Ohyama et al., 2006). However, additional staining was also verified in the companion layer between the upper bulge and the suprabulbar level.

A previously published protocol focusing in human skin uses canine skin as a model since according to authors, there are more similarities between the dog and human skin than the mouse and human skin (Ohyama and Kobayashi, 2012). They describe a protocol in which CD200 was used for separating bulge cells from a population of isolated human keratinocytes. Differently of our study, they use a technique of microdissection to recover only bulge cells, and in the present study, alternatively, we describe a protocol in which the whole skin is placed in digestion, and even after digestion and culture there still are cells positive for CD200. Our protocol is a good alternative to microdissection since it's an easier way to recover bulge stem cells from the skin than the separation of only the bulge region of each of the hairs of the skin. A second important difference between our study and Ohyama and Kobayashi, 2012 is the fact that they were not able to label or separate dog skin bulge cells with CD200, as according to them there were no antibodies specific for CD200 for dog skin. In our study, we prove that there is a population of cells that label for CD200 in culture, by immunocytochemistry analysis, and in immunofluorescence test, by flow cytometry. Besides that, our study shows a comparison of expression between adult and fetus skin, an important aspect to provide information about which is the more suitable source of cells for a possible substitute of skin in regenerative medicine applications.

In canine skin cells, only three previously published studies have identified the presence of mRNA of CD200 (Gerhards et al., 2016; Kobayashi et al., 2010; Ohyama and Kobayashi, 2012). However, neither study investigated both types of labeling of this protein: directly in the skin and after cell culture. Gerhards et al. (2016) tried three different antibodies, and a CD200 label could still not be detected in the immunohistochemistry assay. Similarly in our research, negative results for CD200 and CD34 labeling were observed. The possibility of missing bulge regions in every section studied is present, even though it is mostly because the presence of compound follicles in dogs harshens the longitudinal sections. Hence, the current lack of appropriate antibodies to stain canine CD200 in hair follicles may turn into a major technical concern. We would expect that even when the bulge region is not present, other possible regions could be marked with CD34 and CD200, although this finding was not seen in our study.

Despite our inability to label the bulge niche directly at the skin, a minimal positive population of CD200/CD34 was observed by flow cytometry. Additionally, our cell culture assays (through immunocytochemistry) suggested that CD200 protein is in fact present in canine hair follicle bulge cells, although the levels are highly reduced when compared to other areas of skin tissue. This low population could be explained by the previous data found in other species, as according to Ohyama et al. (2006), the labeling for CD200 in human skin is found mostly in the outer root sheath, as it is two times higher at this location than at the sub-bulge region. In addition, the labeling by the antiCD200 antibody was restricted to the outer root sheath of the bulge region and was not present in the cells in close proximity. These data show that the bulge cell population is found in specific locations of the skin only. Confirmation of specific labeling of CD200 in canine cells isolated from the skin would enable the obtainment of stem cells from the hair follicle bulge region. However, more studies are needed in order to prove the presence of skin cells positive for CD200 and the presence of this protein in dogs as being specific to bulge stem cells.

CD34 is one of the most specific markers for hair follicle cells in mice (Cotsarelis, 2006), and the presence of this protein in canine bulge regions has already been confirmed (Pascucci et al., 2006; Gerhards et al., 2016). Trempus et al. (2003) have shown that the expression of CD34 in follicular bulge keratinocytes in mice is in the same region as the label retaining cells described by Cotsarelis et al. (1990), which also express another marker from bulge keratinocytes known as keratin 15. According to Kloepper et al. (2008), CD200 is one of the most useful markers for bulge cells in humans; however, the presence of this marker has never been directly proven in regard to dog hair follicle bulges. Thus, a double labeling with CD34 is important for localizing the cells in this region.

We have also performed the quantification of CD34 transcripts in fetal and adult skin cell cultures, and the results are very consistent with the flow cytometry analysis. Although no significant difference was observed, fetal cells seem to express slightly more CD34 than adult derived cells. CD200 transcripts were also present in our samples, and their quantification was not significantly different between the adult and fetal cells. Both RT-qPCR and flow cytometry analysis showed very low expression of CD200 and no differences between groups, hence, the detection of CD200 transcripts corroborates the possibility of low specificity of the antibodies used for flow cytometry. Additionally, it is worth noting that this result is different from what occurred with CD34, since the expression of CD200 was equal between the fetal and adult cells.

Double staining was performed by flow cytometry assay. The percentage of the positive population was minimal in comparison to the cultured cells derived from skin tissue, which was expected since only a fraction of the skin was utilized to make the cell cultures, and CD200 and CD34 positive cells were present only at the hair follicle bulge region. It is important to mention that there were considerable differences between the three adult animals' results. A possible explanation is that some factors, such as age of the donor, anatomic region of the skin and size of the hair follicle could affect the presence of CD200 and CD34 in a similar way to that of K19 in human and mouse skin (Michel et al., 1996).

Trempus et al. (2003) found that CD34 positive cells proliferate in cultures, giving rise to big colonies. During the cell culture analysis performed in our experiment, although it was possible to show CD34 expression through immunocytochemistry and gene expression assays, no purified or enriched CD34 positive cells could be isolated and cultured, and therefore, the cell proliferation of this specific phenotype was not possible to be assessed. CD34 has been proven to be present in the bulge region cells; however, it is also present in the outer root sheath of the isthmus, the suprabulbar region, and in various other regions depending on the hair follicle cycle phase (Gerhards et al., 2016). Therefore, CD34 alone is not a specific marker for the presence of bulge cells.

OCT4 is known as a pluripotency marker (Shi and Jin, 2010). However, it has already been reported to be present in fetal stem cell lines (Ryan et al., 2013). In a previous study in humans, Yu et al. (2006) cultured skin stem cells in a medium akin to an embryonic stem cell culture medium; they obtained agglomerated non-adherent spheres of cells, with few of them being positive for OCT4 (Yu et al., 2006).Although our cellular culture conditions were different than those used by Yu et al., it was possible to identify OCT4 positive cells in our fetal cell samples.

\section{Conclusions}

Proteins that may help characterize stem cells in the hair follicle 

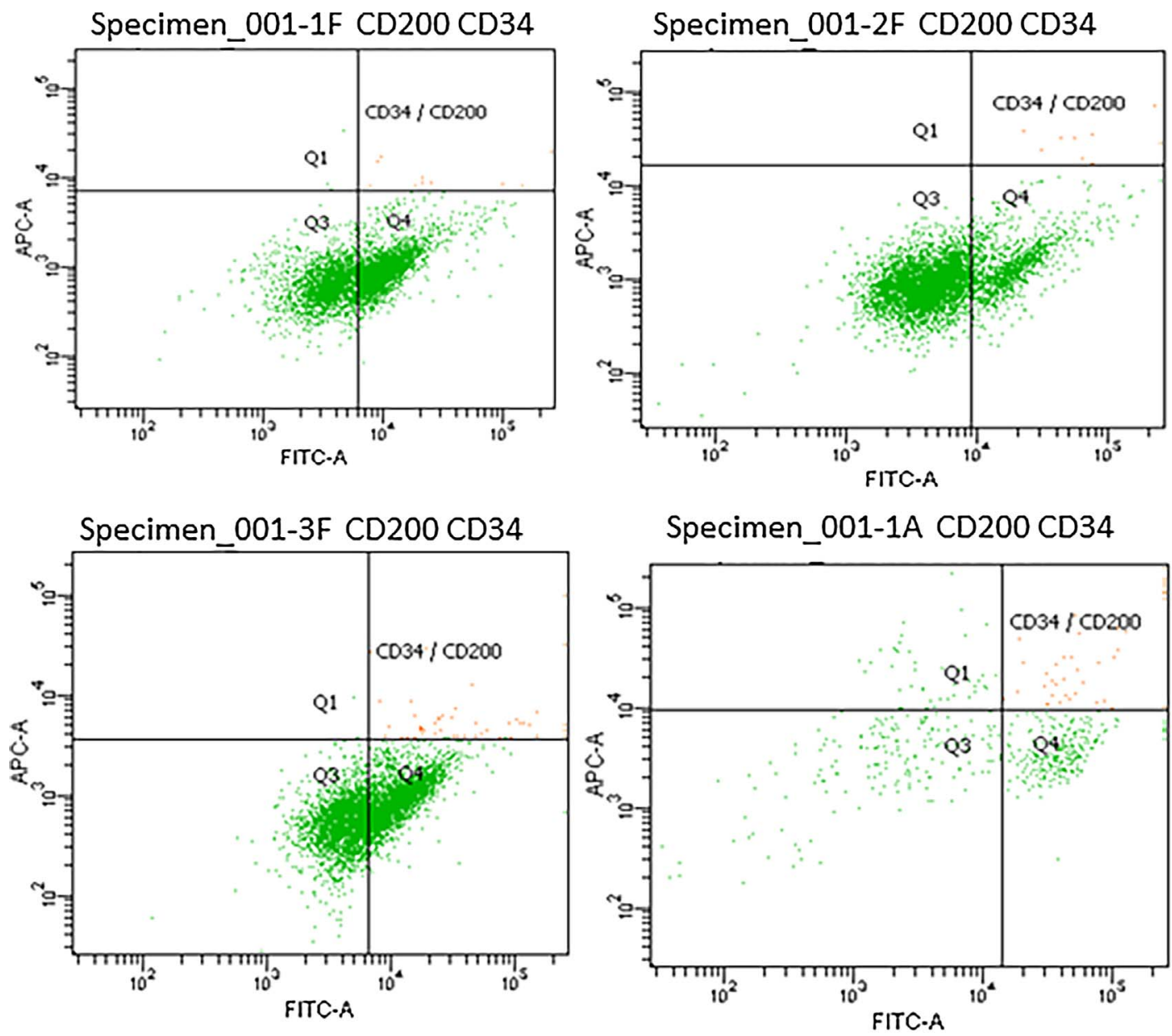

\section{Specimen_001-2A CD200 CD34}
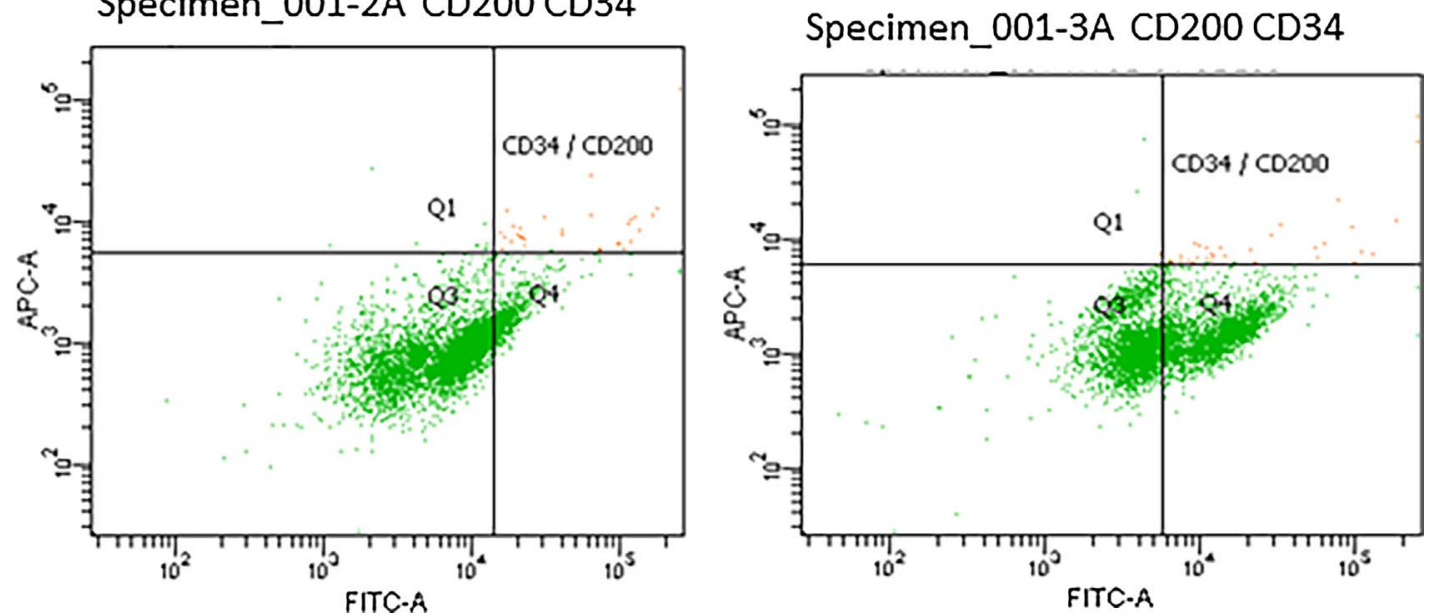

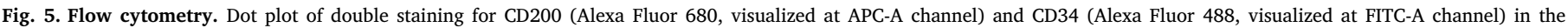
experiments relative to fetal $(1 \mathrm{~F}, 2 \mathrm{~F}$ and $3 \mathrm{~F})$ and adult $(1 \mathrm{~A}, 2 \mathrm{~A}$ and $3 \mathrm{~A})$ cell lines.

bulge region, CD200, CD34 and OCT4, were analyzed in adult and fetus cell cultures. CD34 and CD200 were not observed directly in the skin. Flow cytometry results show a low percentage of cells positive for these markers, which suggests that with the simple enzymatic digestion and cell culture methods used for this experiment, it is possible to obtain stem cells from the bulge region of the canine hair follicle. Additionally, we could verify the presence of transcripts of the 3 genes, CD200, CD34 and OCT4, and although not significantly different, CD34 and OCT4 expression were slightly higher in the fetal cells, rather than the adult cells, and CD200 had a similar expression in both fetal and adult cells. These results are in accordance with the flow cytometry results. There is still a need to develop more specific and standardized antibodies for these proteins in canines, which would make it possible to use them in the separation of cells and future characterizations. Sorting cells using the FACS technique is necessary for identifying cell characteristics such as proliferation and differentiation, especially in regard to obtaining purified populations. Canine bulge cells have been studied, although contradicting results have been reported; this study is one of the first steps towards developing new research involving this niche in canine species. 


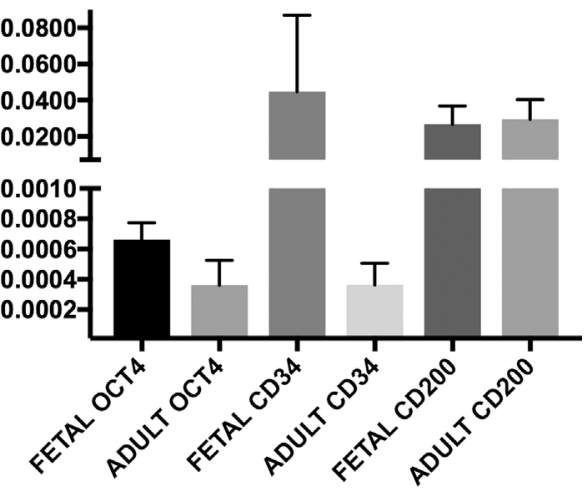

\section{GENES / PERIODS}

Fig. 6. Quantitative reverse transcription polymerase chain reaction (RT-qPCR). OCT4, CD34 and CD200 are present in both the adult and fetal cells. Although the fetal cells seemed to have higher levels of OCT4 and CD34, no difference was observed in the frequency among the three genes.

\section{Funding sources}

Coordenação de Aperfeiçoamento de Pessoal de Nível Superior (CAPES) and FAPESP (2015/26818-5).

\section{Acknowledgments}

We acknowledge Professor Áureo Evangelista Santana for allowing the use of the Flow Cytometer of the "Laboratório de Patologia Clínica Veterinária Professor Dr. Joaquim Martins Ferreira Neto" from FCAV UNESP, as well as Jaboticabal and Tais Harumi de Castro Sasahara for their assistance with immunofluorescence assays.

\section{References}

Blanpain, C., Fuchs, E., 2006. Epidermal stem cells of the skin. Annu. Rev. Cell Dev. Biol. 22, 339-373. http://dx.doi.org/10.1146/annurev.cellbio.22.010305.104357.

Cotsarelis, G., Sun, T.T., Lavker, R.M., 1990. Label-retaining cells reside in the bulge area of pilosebaceous unit: implications for follicular stem cells, hair cycle, and skin carcinogenesis. Cell 61, 1329-1337.

Cotsarelis, G., 2006. Epithelial stem cells: a folliculocentric view. J. Invest. Dermatol. 126, 1459-1468.

Evans, H.E., Sack, W.O., 1973. Prenatal development of domestic and laboratory mammals: growth curves: external features and selected references. Zentralbl. Veterinarmed. C 2, 11-45.

Gerhards, N.M., Sayar, B.S., Origgi, F.C., Galichet, A., Müller, E.J., Welle, M.M., Wiener, D.J., 2016. Stem cell-associated marker expression in canine hair follicles. J. Histochem. Cytochem. 64, 190-204. http://dx.doi.org/10.1369/ 0022155415627679.

Green, H., 2008. The Birth of Therapy with Cultured Cells. pp. 897-903. http://dx.doi. org/10.1002/bies.20797.

Inoue, K., Aoi, N., Sato, T., Yamauchi, Y., Suga, H., Eto, H., Kato, H., 2009. Differential expression of stem-cell-associated markers in human hair follicle epithelial cells. Lab. Invest. 89, 844-856. http://dx.doi.org/10.1038/labinvest.2009.48.

Kloepper, J.E., Tiede, S., Brinckmann, J., Reinhardt, D.P., Meyer, W., Faessler, R., Paus, R., 2008. Immunophenotyping of the human bulge region: the quest to define useful in situ markers for human epithelial hair follicle stem cells and their niche. Exp. Dermatol. 17, 592-609. http://dx.doi.org/10.1111/j.1600-0625.2008.00720.x.

Kobayashi, T., Iwasaki, T., Amagai, M., Ohyama, M., 2010. Canine follicle stem cell candidates reside in the bulge and share characteristic features with human bulge cells. J. Invest. Dermatol. 130, 1988-1995. http://dx.doi.org/10.1038/jid.2010.68.

Lanza, R.P., Robert, P., Atala, A., 2012. Handbook of stem cells. Adult and Fetal Stem Cells, vol. 2 Elsevier/AP.

Lavker, R.M., Sun, T.-T., 2000. Epidermal stem cells: properties, markers, and location. Proc. Natl. Acad. Sci. 97, 13473-13475. http://dx.doi.org/10.1073/pnas. 250380097.

Lyle, S., Christofidou-Solomidou, M., Liu, Y., Elder, D.E., Albelda, S., Cotsarelis, G., 1998. The C8/144 B monoclonal antibody recognizes cytokeratin 15 and defines the location of human hair follicle stem cells. J. Cell Sci. 111 (Pt 2), 3179-3188.

Michel, M., Török, N., Godbout, M.J., Lussier, M., Gaudreau, P., Royal a, Germain, L., 1996. Keratin 19 as a biochemical marker of skin stem cells in vivo and in vitro: keratin 19 expressing cells are differentially localized in function of anatomic sites, and their number varies with donor age and culture stage. J. Cell Sci. 109 (Pt 5), 1017-1028. http://dx.doi.org/10.1007/BF02634255.

Morris, R.J., Potten, C.S., 1999. Highly persistent label-retaining cells in the hair follicles of mice and their fate following induction of anagen. J. Invest. Dermatol. 112, 470-475. http://dx.doi.org/10.1046/j.1523-1747.1999.00537.x.

Najafzadeh, N., Sagha, M., Heydari Tajaddod, S., Golmohammadi, M.G., Massahi Oskoui, N., Deldadeh Moghaddam, M., 2015. In vitro neural differentiation of CD34 (+) stem cell populations in hair follicles by three different neural induction protocols. In Vitro Cell. Dev. Biol. Anim. 51, 192-203. http://dx.doi.org/10.1007/s11626-014-9818-2.

Ohyama, M., Kobayashi, T., 2012. Isolation and characterization of stem cell-enriched human and canine hair follicle keratinocytes. In: Singh, S.R. (Ed.), Somatic Stem Cells: Methods and Protocols. Humana Press, Totowa, NJ, pp. 389-401. http://dx. doi.org/10.1007/978-1-61779-815-3_24.

Ohyama, M., Terunuma, A., Tock, C.L., Radonovich, M.F., Pise-Masison, C.A., Hopping, S.B., Brady, J.N., Udey, M.C., Vogel, J.C., 2006. Characterization and isolation of stem cell-enriched human hair follicle bulge cells. J. Clin. Invest. 116, 249-260. http://dx.doi.org/10.1172/JCI26043.

Pascucci, L., Mercati, F., Gargiulo, A.M., Pedini, V., Sorbolini, S., Ceccarelli, P., 2006 CD34 Glycoprotein Identifies Putative Stem Cells Located in the Isthmic Region of Canine Hair Follicles.

Pfaffl, M.W., 2001. A new mathematical model for relative quantification in real-time RTPCR. Nucleic Acids Res. 29, e45. http://dx.doi.org/10.1093/nar/29.9.e45.

Pieri, N., Souza, A.F., Casals, J.B., Roballo, K., Ambrósio, C.E., Martins, D.S., 2015. Comparative development of embryonic age by organogenesis in domestic dogs and cats. Reprod. Domest. Anim. 50, 625-631. http://dx.doi.org/10.1111/rda.12539.

Poblet, E., Jiménez, F., Godínez, J.M., Pascual-Martín, A., Izeta, A., 2006. The immunohistochemical expression of CD34 in human hair follicles: a comparative study with the bulge marker CK15. Clin. Exp. Dermatol. 31, 807-812. http://dx.doi.org/10. 1111/j.1365-2230.2006.02255.x.

R Core Team, R.D.C.T, 2013. A Language and Environment for Statistical Computing.

Rosenblum, M.D., Olasz, E., Woodliff, J.E., Johnson, B.D., Konkol, M.C., Gerber, K.A. Orentas, R.J., Sandford, G., Truitt, R.L., 2004. CD200 is a novel p53-target gene in volved in apoptosis-associated immune tolerance. Blood 103, 2691-2698. http://dx. doi.org/10.1182/blood-2003-09-3184.

Ryan, J.M., Pettit, A.R., Guillot, P.V., Chan, J.K.Y., Fisk, N.M., 2013. Unravelling the pluripotency paradox in fetal and placental mesenchymal stem cells: oct-4 expression and the case of the emperor's new clothes. Stem Cell Rev. Reports 408-421. http:// dx.doi.org/10.1007/s12015-011-9336-5.

Shi, G., Jin, Y., 2010. Role of Oct4 in maintaining and regaining stem cell pluripotency. Stem Cell Res. Ther. 1, 39. http://dx.doi.org/10.1186/scrt39.

Tan, K.K.B., Salgado, G., Connolly, J.E., Chan, J.K.Y., Lane, E.B., 2014. Characterization of fetal keratinocytes, showing enhanced stem cell-like properties: a potential source of cells for skin reconstruction. Stem Cell Rep. 3, 324-338. http://dx.doi.org/10. 1016/j.stemcr.2014.06.005.

Taylor, G., Lehrer, M.S., Jensen, P.J., Sun, T.T., Lavker, R.M., 2000. Involvement of follicular stem cells in forming not only the follicle but also the epidermis. Cell 102, 451-461.

Trempus, C.S., Morris, R.J., Bortner, C.D., Cotsarelis, G., Faircloth, R.S., Je, M., Raymond, W., 2003. Enrichment for living murine keratinocytes from the hair follicle bulge with the cell surface marker CD34. J. Invest. Dermatol. 501-511.

Tumbar, T., Guasch, G., Greco, V., Blanpain, C., Lowry, W.E., Rendl, M., Fuchs, E., 2004. Defining the epithelial stem cell niche in skin. Science 303, 359-363. http://dx.doi. org/10.1126/science.1092436.

Yu, H., Fang, D., Kumar, S.M., Li, L., Nguyen, T.K., Acs, G., Herlyn, M., Xu, X., 2006. Isolation of a novel population of multipotent adult stem cells from human hair follicles. Am. J. Pathol. 168, 1879-1888. http://dx.doi.org/10.2353/ajpath.2006. 051170 .

Yu, K., Chen, Z., Gorczynski, R., 2013. Effect of CD200 and CD200R1 expression within tissue grafts on increased graft survival in allogeneic recipients. Immunol. Lett. 149, 1-8. http://dx.doi.org/10.1016/j.imlet.2012.11.004. 